\title{
When the tide goes out: health workforce in rural, remote and Indigenous communities
}

\author{
Richard B Murray and lan Wronski
}

$\mathrm{I}$ $\mathrm{n}$ the city of tomorrow, the health workforce is likely to have characteristics already familiar to the bush. In much of rural and remote Australia, the medical generalist is a jack-of-alltrades; specialists function as true consultants; the clinical roles of other health care workers are extended (eg, nurses, allied health practitioners, pharmacists, Aboriginal health workers and dentists); mutual reliance and teamwork are essential; and communities cannot afford to take their local services for granted. As the workforce tide recedes with health workforce shortages becoming more widespread, ${ }^{1}$ it will further expose the poor and the disadvantaged, as well as the populations of regional and outer metropolitan areas and the less alluring suburbs. What lessons might be adapted from the bush? And how are the health care needs of rural, remote and Indigenous communities to be met?

Thirty-four per cent of all Australians live outside major cities, as do $70 \%$ of Aboriginal and Torres Strait Islander peoples. However, the share of the total health workforce outside urban areas is considerably less - $23 \%$ of medical specialists, $27 \%$ of general practitioners, $34 \%$ of nurses and $25 \%$ of physiotherapists. ${ }^{2}$

As the shortage of doctors and nurses is global, the health labour market is increasingly internationalised. ${ }^{3}$ For Australia (and rural areas in particular), this means not only competing for medical, nursing and allied health graduates in an expensive international marketplace, but also a loss of our health graduates to more lucrative posts, particularly in the United Kingdom and North America. There is concern that high levels of Australian student debt may accelerate this loss.

What is known about encouraging health professionals to practise in rural and remote areas? The evidence for the success of the "rural pipeline" in medical education and training is now beyond doubt ${ }^{4,5}$ and is consistent with early data from nursing and allied health. ${ }^{6-8}$ This "pipeline" involves recruiting students from rural backgrounds, delivering training in the regions, rural curriculum providing repeated rural exposures, and building regionally based postgraduate training pathways.

Despite useful gains (around $20 \%$ of medical students are now classified as being of rural origin), the rural medical workforce still does not reflect population share, and nursing and allied health have a long way to go. In nursing, the loss of regional infrastructure for clinical teaching that accompanied the education reforms in the 1980s and 1990s has yet to be offset by investment in rural and regional university programs. Partly as a result, nursing looks likely to suffer an even greater shortage than medicine. ${ }^{9}$ Experience with flexible, small-scale delivery of nursing programs in locations such as Thursday Island and Mount Isa has been encouraging, ${ }^{10}$ but much more investment is needed.

There are real challenges in building a regional "teaching health system". The private sector is underutilised, and ambivalence about academic teaching and research is common in rural public hospitals, in part because of the lack of clarity over clinical teaching as core business, and resource constraints. ${ }^{11}$ A lack of political commitment to the inextricable relationship between clinical teaching, research and high quality health services adds to the tensions as to who should fund teaching and training activities.

\section{ABSTRACT}

- There is compelling evidence for the success of the "rural pipeline" (rural student recruitment and rurally based education and professional training) in increasing the rural workforce.

- The nexus between clinical education and training, sustaining the health care workforce, clinical research, and quality and safety needs greater emphasis in regional areas.

- A "teaching health system" for non-metropolitan Australia requires greater commitment to teaching as core business, as well as provision of infrastructure, including accommodation, and access to the private sector.

- Workforce flexibility is mostly well accepted in rural and remote areas. There is room for expanding the scope of clinical practice by non-medical clinicians in both an independent codified manner (eg, nurse practitioners) and through flexible local medical delegation (eg, practice nurses, Aboriginal health workers, and therapists).

- The imbalance between subspecialist and generalist medical training needs to be addressed.

- Improved training and recognition of Aboriginal health workers, as well as continued investment in Indigenous entry to other health professional programs, remain policy priorities.

MJA 2006; $185: 37-38$

Financially sustainable models of private teaching practice that would facilitate vertical integration of clinical education are not well established or understood.

Loss of senior clinicians and increasing reliance by hospitals on short-term employment contracts, agency staff and internationally trained graduates put pressure on clinical teaching and accommodation. The wholesale decommissioning of hospital accommodation for students in regional areas demonstrates a general lack of strategic commitment to regional teaching and development of the next generation of health professionals. As state governments ratchet up salaries for hospital-salaried medical officers in response to the national workforce shortage and political heat (as occurred recently in Queensland), large pay disparities between the university system and public hospitals threaten the viability of clinical academic medicine, as well as Aboriginal health services.

Conventional models of health service delivery also need to be revisited. The stand-alone model of isolated solo practice in rural areas lacks heroes, advocates and appeal for many medical graduates, who are increasingly turning to part-time medical work (both men and women) ${ }^{12}$ Already, flexible approaches to clinical task delegation and a team-oriented approach are widely accepted in rural and remote areas. Nurses, Aboriginal health workers (AHWs) and therapists routinely exercise an extended scope of clinical practice that reflects community needs, often informally developed while working alongside doctors. There are some mechanisms to support extended 
clinical practice (eg, standard treatment manuals and standing orders linked to poisons legislation reform ${ }^{13}$ ). However, the ambiguity about where the responsibility lies can leave nurses and AHWs exposed where practice falls outside the letter of the law.

The development of nurse practitioner legislation in most Australian jurisdictions ${ }^{9}$ now provides a mechanism to link advanced training with codified, independent, advanced clinical practice by nurses while working in an approved setting. To date, this has generally been for specialised jobs in tertiary hospitals rather than in the bush. A complementary approach to the codified independent clinical practice model is a framework for less regulated, flexible delegation of clinical duties by doctors to other members of the health team locally. The latter approach underpins recent "practice nurse" incentives, which now include Medicare item numbers for wound dressings, immunisations and Pap smears when performed under delegation by registered nurses and enrolled nurses (and AHWs in the Northern Territory). Both approaches are needed: no one professional group represents "the answer".

The rural experience strongly suggests that the balance of community investment in generalist versus subspecialist medical training requires review. The struggle to win recognition for the discipline of "rural medical generalist" as a specialty ${ }^{14}$ reflects a need for training pathways and professional recognition of doctors who can provide comprehensive clinical care across the primary and secondary care continuum. The strategic importance of repopulating the broad skills-set, generalist workforce is gaining political acceptance and momentum.

However, as education and training systems for clinical practice are reviewed, there is a risk that the need for greater workforce flexibility will translate to yet more years being added to already lengthy "monoprofessional", "monospecialty", serial training pathways. ${ }^{15}$ The health workforce will not be expanded by drawing only on the existing health professional pool for retraining (the phenomenon of "churning") - unless this results in significant improvements to retention or recruitment. There is merit in offering short generic training pathways to equip a range of health workers for expanded clinical roles under delegation (perhaps along the lines of the US physician assistant).

Aboriginal health workers have been an important strategy for improving access to health care by Indigenous peoples. They have had expanded clinical roles for decades, particularly in northern and remote Australia and the Aboriginal community-controlled health service sector. However, in many locations, the "AHW" designation has been used inconsistently, and loosely applied to workers with liaison, transport or advocacy functions who lack clinical training. There are already examples where AHWs provide advanced care in emerging areas of need, such as haemodialysis, as well as in midwifery. It is important that interprofessional rivalnies and trends towards credentialling for common clinical duties do not erode opportunities for AHWs to train and practise. The development of nationally consistent competency standards and qualifications for AHWs with clinical practice roles is welcome, and now needs to be translated more clearly to job specifications and training pathways.

With a few notable exceptions, the number of Indigenous students entering undergraduate health courses has been disappointing, a product of many factors underlying educational disadvantage, including poverty, remoteness and negative experiences in schools that are often under-resourced. This goes back to primary school: around $40 \%$ of Indigenous students did not meet national Year 7 reading benchmarks in 2001 (12\% for non-Indigenous students). Those from remote areas fared significantly worse (evidenced by a $70 \%$ failure rate in the Northern Territory). ${ }^{16}$ Nevertheless, with Indigenous community partnerships, regional accessibility and well-resourced programs for student support, it is possible to substantially increase the numbers of Indigenous students in professional training.

The news from the bush is mixed. We know what needs to be done to build rural workforce, and many initiatives of the past 10 years are delivering results, but major inequities remain. We must strongly advocate the nexus between clinical training, research, sustaining health workforce, and health care quality and safety in a regionalised "teaching health system". And health leaders would do well to study rural solutions - they will be needed in cities before too long.

\section{Competing interests}

None identified.

\section{Author details}

Richard B Murray, MB BS, MPHTM, FACRRM, Associate Professor and Planning Director, Rural Clinical School, ${ }^{1}$ College Censor ${ }^{2}$

lan Wronski, MB BS, SM(Epi)(Harvard), FAFPHM, Pro Vice-Chancellor'

1 Faculty of Medicine, Health and Molecular Sciences, James Cook University, Townsville, QLD.

2 Australian College of Rural and Remote Medicine, Brisbane, QLD. Correspondence: richard.murray@jcu.edu.au

\section{References}

1 Joyce CM, McNeil JJ, Stoelwinder JU. More doctors, but not enough: Australian medical workforce supply 2001-2012. Med J Aust 2006; 184: 441-446.

2 Australian Institute of Health and Welfare. Health and community services labour force 2001. National Health Labour Force Series number 27. ABS Cat No 8936.0 .

3 Mullan F. The metrics of the physician brain drain. N Engl J Med 2005; 353 : $1810-1818$.

4 Hsueh W, Wilkinson T, Bills J. What evidence-based undergraduate interventions promote rural health? N Z Med J 2004; 117 : U1117.

5 Dunbabin JS, Levitt L. Rural origin and rural medical exposure: their impact on the rural and remote medical workforce in Australia. Rural Remote Health 2003; 3: 212.

6 Lee S, Mackenzie L. Starting out in rural New South Wales: the experiences of new graduate occupational therapists. Aust J Rural Health 2003; 11: $36-43$.

7 Playford D, Larson A, Wheatland B. Going country: rural student placement factors associated with future rural employment in nursing and allied health. Aust $J$ Rural Health 2006; 14: 14-19.

8 Courtney M, Edwards $H$, Smith S, et al. The impact of rural clinical placement on student nurses' employment intentions. Collegian 2002; 9: 12-18.

9 Australian Government. The patient profession: time for action. Report on the inquiry into nursing. Senate Community Affairs Committee 2002. Available at: http://www.aph.gov.au/senate/committee/clac_ctte/completed_inquiries/ 2002-04/nursing/report/ (accessed Feb 2006).

10 Usher $\mathrm{K}$, Lindsay D, Mackay W. An innovative nurse education program in the Torres Strait islands. Nurse Educ Today 2005; 25: 437-441.

11 Jones GI, Alford KA, Russell UJ, Simmons D. Removing the roadblocks to medical and health student training in rural hospitals in Victoria. Aust $J$ Rural Health 2003; 11: 218-223.

12 Australian Health Workforce Advisory Committee. Annual Report 2003-04. Sydney: AHWAC, 2004. Available at: http://www. healthworkforce.health.nsw.gov.au/amwac/ahwac/reports.html (accessed Feb 2006).

13 Central Australian Rural Practitioners' Association. CARPA standard treatment manual. 4th ed. Alice Springs: CARPA, 2003.

14 Wronski l. Rural and remote medicine: comes of age [editorial]. Aust J Rural Health 2003; 11: 161-162.

15 Duckett SJ. Health workforce design for the 21st century. Aust Health Rev 2005; 29: 201-210.

16 Ministerial Council on Education, Employment, Training and Youth Affairs. National report on schooling in Australia preliminary paper, National benchmark results reading writing and numeracy. Available at: http:// uww.mceetya.edu.au/mceetya/ (accessed Feb 2006).

(Received 19 Mar 2006, accepted 21 May 2006) 